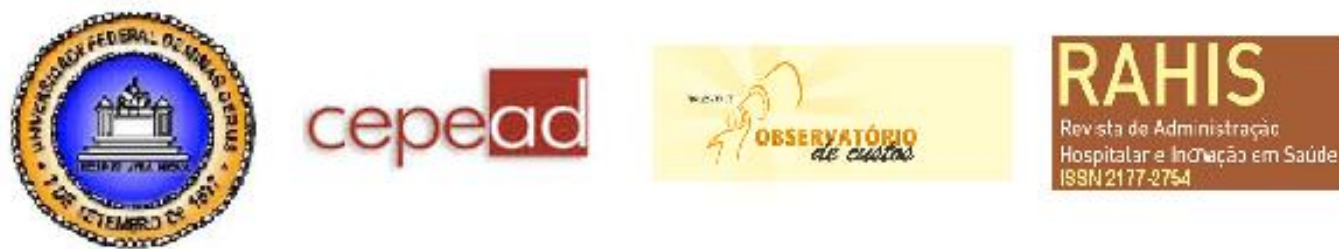

\title{
CELULARES E O TRABALHO: UM ESTUDO SOBRE OS IMPACTOS NO TRABALHO E PÓS-TRABALHO
}

\author{
Renata F. Baldanza \\ Universidade Federal da Paraíba - UFPB \\ renatabaldanza@gmail.com \\ Vanessa Lins de Souza \\ Universidade Federal da Paraíba - UFPB \\ vanessalinssouza@ hotmail.com \\ Tito Jose Castro Amorim \\ Universidade Federal da Paraíba- UFPB \\ titoamorim.br@gmail.com \\ Milka Alves Correia Barbosa \\ Universidade Federal da Paraíba - UFPB \\ $\underline{\text { milka.correia@gmail.com }}$ \\ Nelsio Rodrigues de Abreu \\ Universidade Federal da Paraíba - UFPB \\ nelsio@gmail.com \\ Submetido em: 30/03/2015 \\ Artigo aceito em: 28/08/2016 \\ DOI 10.21450/rahis.v13i2.2816
}

\section{RESUMO}

As tecnologias móveis têm cada vez mais sido utilizadas nas empresas de forma estratégica, a fim de viabilizar processos e práticas cotidianas nas organizações, que antes eram realizadas de modo muito mais centralizado e desarticulado como, por exemplo, as próprias práticas comunicativas internas. Neste sentido, esta pesquisa, de natureza qualitativa, objetivou analisar os impactos do uso dos telefones celulares no ambiente de trabalho e fora deste, na perspectiva dos gestores. Este estudo então se propõe a sanar a questão de pesquisa: Como o uso deste dispositivo móvel, normalmente em tempo integral, pode impactar o cotidiano no trabalho e pós trabalho de gestores de empresas e/ou organizações? Partiu-se do princípio que os telefones celulares, por serem um artefato móvel de comunicação de uso contínuo, que suporta várias ferramentas que facilitam o dia a dia das pessoas e estende as práticas comunicativas síncronas e assíncronas, podem afetar positiva e negativamente o cotidiano de trabalho e social dos envolvidos. Para tanto, foram realizadas dez entrevistas semiestruturadas e em profundidade com gestores da cidade de João Pessoa/PB, responsáveis pelos níveis de planejamento estratégico e tático das empresas. Os dados coletados foram submetidos à análise de discurso e refletidos à luz da fundamentação teórica. Ficou evidenciado nas falas dos gestores, de maneira unânime, que o telefone celular facilita as atividades organizacionais nos aspectos de resoluções de conflitos, nas práticas internas da empresa, nos andamentos de processos e nas negociações. Embora o telefone celular possa trazer inúmeras vantagens competitivas para a empresa, verificou-se nas falas dos participantes que o telefone celular acarreta ao mesmo tempo um prejuízo na vida social e familiar dos mesmos.

Palavras-chave: Telefones Celulares, Trabalho, Comunicação. 


\title{
MOBILE PHONES AND WORK: A STUDY ABOUT THE IMPACT AT WORK AND POST-WORK
}

\begin{abstract}
Mobile technologies have been increasingly used in a strategic way companies in order to facilitate processes and everyday practices in organizations, which were previously carried out much more centralized and disjointed, such as their own internal communication practices. In this sense, this research was qualitative, aimed to analyze the impacts of the use of cell phones in the workplace and outside it, the perspectives of managers. This study then proposes to remedy the research question: How to use this mobile device, usually fulltime, can impact the daily lives at work and after work business managers and/or organizations? it was assumed that cell phones, being a mobile device of continuous use communication which supports a variety of tools that facilitate the daily lives of people and extends the synchronous and asynchronous communication practices, can positively and negatively affect the daily life of work and social stakeholder. For that ten semi-structured and in depth with managers of the city of João Pessoa/PB, responsible for the strategic and tactical levels of planning enterprises interviews were conducted. Data were submitted to analysis of discourse and reflected the light of the theoretical foundation. Evidenced in the statements of managers unanimously way, the mobile phone facilitates organizational activities in aspects of conflict resolution, internal company practices, the movements of processes and negotiations. Although the cell phone can bring numerous competitive advantages for the company, it was found in the speeches of the participants that cell phone at the same time entails a loss in the same social and family life.
\end{abstract}

Keywords: Mobile Phones, Work, Communication.

\section{MÓVILES Y TRABAJO: UN ESTUDIO SOBRE EL IMPACTO EN EL TRABAJO Y POST-TRABAJO}

\section{RESUME}

Las tecnologías móviles se han utilizado estratégicamente cada vez más por las empresas, con el fin de hacer que los procesos y las prácticas cotidianas en las organizaciones, que se llevaron a cabo de una manera mucho más centralizada y desarticulada, como ejemplo sus propias prácticas de comunicación interna. En este sentido, ésta investigación cualitativa tiene el objetivo de analizar los impactos del uso de teléfonos móviles en el lugar de trabajo y fuera de él desde las perspectivas de los gerentes. Este estudio propone entonces para poner solución a la pregunta de investigación: ¿Cómo utilizar este dispositivo móvil bentónica, por lo general a tiempo completo, puede tener un impacto en la vida cotidiana en el trabajo y después de administradores y/o las organizaciones empresariales trabajo? se asumió teléfonos celulares Que, siendo el dispositivo móvil de comunicación de uso continuo que soporta una variedad de herramientas Que facilitar la vida diaria de las personas y se extiende a las prácticas de comunicación síncrona y asíncrona, positiva y negativamente puede afectar a la vida cotidiana de trabajo y los grupos de interés social. Por lo tanto, hubo diez entrevistas semiestructuradas y en profundidad con los administradores de la ciudad de João Pessoa / PB, responsables del nivel de planificación estratégica y táctica de las empresas. Se presentaron los datos recogidos al análisis del discurso y reflejan la luz de la fundamentación teórica. Era evidente en las declaraciones de administradores, por unanimidad, que el teléfono móvil facilita las actividades de organización en los aspectos de la resolución de conflictos, las prácticas internas de la empresa, los procesos y negociaciones de movimientos. Aunque el teléfono celular puede traer muchas ventajas competitivas para la empresa, se encontró en los discursos de los participantes de que el teléfono celular provoca tanto una pérdida en la vida social y familiar de los mismos.

Palabras clave: Telefonía móvil, trabajo, comunicación.

Agradecimento: Conselho Nacional de Desenvolvimento Científico e Tecnológico - CNPq. 


\section{INTRODUÇÃOO}

$\mathrm{Na}$ contemporaneidade, o tempo e a rapidez na circulação das informações tornaramse fundamentais para o sucesso das empresas. Uma informação mal interpretada ou não enviada em tempo hábil pode gerar grandes transtornos às organizações. Todavia, os artefatos tecnológicos que permitem a comunicação rápida e em mobilidade como os telefones celulares têm alterado as formas de transitar informações que dão suporte aos processos cotidianos como resolução de conflitos, processo decisório, andamento de processos e práticas internas dentre outros.

Isso somente é possível primeiramente porque este dispositivo permite a comunicação móvel entre as partes responsáveis pela gestão e pelo funcionamento tático e operacional da empresa e, segundo, porque suas evoluções no que se refere aos recursos de comunicação disponibilizados como internet, bluetooth, mensagens instantâneas de texto (sms), e de imagens e vídeo ( $m m s$ ), envio de e-mails com arquivos, entre outros, além da própria ligação convencional, permitem trocas de informações, dados e arquivos que maximizam todos os processos acima citados.

Situada nesta discussão, apresenta-se a seguinte questão de pesquisa: Como o uso deste dispositivo móvel, normalmente em tempo integral, pode impactar o cotidiano no trabalho e pós trabalho de gestores de empresas e/ou organizações? Partiu-se justamente do princípio que os telefones celulares, por serem um artefato móvel de comunicação de uso contínuo, e que suporta várias ferramentas que facilitam o dia a dia das pessoas e estende as práticas comunicativas síncronas e assíncronas, podem afetar positiva e negativamente o cotidiano de trabalho e social dos envolvidos.

Fäy (2005) compreende a introdução das novas mídias no ambiente de trabalho como uma ferramenta capaz tanto de facilitar o andamento das atividades, como também de criar possíveis ruídos que poderiam dificultar as comunicações entre setores ou trabalhadores localizados em diferentes espaços geográficos. Do mesmo modo, Mooallem (2008) ressalta que os telefones celulares têm auxiliado muito no dia a dia das empresas, embora seu uso possa também impactar negativamente em alguns aspectos.

Para tanto, o estudo enfocou aspectos que vislumbram analisar as afetações do uso dos telefones celulares, considerando-os como artefato de comunicação interna das organizações, bem como seus efeitos não somente nas práticas de trabalho dos gestores como também fora do ambiente de trabalho, quando utilizado para questões profissionais em outros ambientes senão o ambiente organizacional. Concomitantemente, ainda averigua como e em que medida os telefones celulares dão suporte à operacionalização de resoluções cotidianas de tarefas, funções e processos.

Convém ressaltar a relevância deste estudo quando se considera a pouca quantidade de pesquisas no Brasil que enfatizem esta temática e tratam deste fenômeno em sua totalidade. No que se refere a contribuição para avanços acadêmicos, aponta-se ainda a possibilidade de apresentar um novo olhar sobre efeitos de mídias interativas nas práticas de comunicação interna das empresas, principalmente em se tratando de um artefato multifuncional, móvel e híbrido. A pesquisa pode auxiliar os gestores na compreensão de como lidar melhor com os telefones celulares, de como são afetados por eles e quais as consequências disso para a organização.

\section{REVISÃO DE LITERATURA}

\subsection{Os telefones celulares no Brasil: evolução e perspectivas}

A telefonia móvel foi introduzida no Brasil em 1972 por um sistema anterior à tecnologia celular, um sistema de baixa capacidade, com tecnologia IMTS (Improved Mobile Telephone System). Em 1984, deu-se início à análise de sistemas de tecnologia celular sendo definido o padrão americano, analógico AMPS (Advanced Mobile Phone System ou Sistema 
de Comunicação de Telefonia Celular), como modelo a ser introduzido (foi implantado, também, em todos os outros países do continente americano e em alguns países da Ásia e Austrália). O padrão AMPS introduzido obedecia rigorosamente a formatação em uso nos Estados Unidos (MACHADO, 2016).

Posteriormente, com o aumento da demanda, o Ministério das Comunicações expandiu a Banda de frequência para o sistema móvel celular e utilizou o padrão E-AMPS (Extended AMPS). Em 1990, o Rio de Janeiro é a primeira cidade brasileira a usar a Telefonia Móvel Celular e foi seguido por Campo Grande, Belo Horizonte e Goiânia. Em 1993 inaugurou-se a Telefonia Móvel Celular em São Paulo, e em novembro deste mesmo ano a Telesp Celular lança o seu celular digital (MACHADO, 2016).

Em se tratando de evolução, Pavlik (2008) afirma que a direção futura das tecnologias de reprodução de imagens digitais reflete três tendências principais. Primeiramente, as tecnologias de reprodução de imagem estão em uma trajetória de miniaturização crescente. Quanto a isto, apesar de se perceber que nos últimos dois anos (2015 e 2016) especificamente os smartphones tenham aumentado o tamanho de suas telas para facilitar o uso de recursos mais elaborados e leitura, a tendência ainda é a de mobilidade compacta.

Segundo, dispositivos com design de fácil usabilidade e que continuam melhorando, especialmente para usuários sem treinamento avançado (PAVLIK, 2008). Isso pode ser facilmente observado nos modelos mais avançados de smartphones lançados nos últimos anos, cujas interfaces são intuitivas, com aplicativos geralmente de fácil utilização e recursos inteligentes de memória do próprio dispositivo que cria padrões de ação e direcionam o usuário mais rapidamente ao que ele pretende. $\mathrm{O}$ ator aponta ainda que como terceira tendência, e não necessariamente relacionado às duas tendências precedentes, cada vez mais, os dispositivos são capazes de funções múltiplas.

Complementando tais desígnios, Lemos destaca que o celular pode ser caracterizado como um Dispositivo Híbrido Móvel de Conexão Multirredes (DHMCM), minudenciando que

o que chamamos de telefone celular é um Dispositivo (um artefato, uma tecnologia de comunicação); Híbrido, já que congrega funções de telefone, computador, máquina fotográfica, câmera de vídeo, processador de texto, GPS, entre outras; Móvel, isto é, portátil e conectado em mobilidade funcionando por redes sem fio digitais, ou seja, de Conexão; e Multirredes, já que pode empregar diversas redes, como Bluetooth e infravermelho, para conexões de curto alcance entre outros (LEMOS, 2007, p. 2).

Assim, integra o autor, "os DHMCM aliam a potência comunicativa (voz, texto, foto, vídeos), a conexo em rede, a mobilidade por territórios informacionais" (LEMOS, 2006). Neste sentido, este conceito se adapta sobremaneira à lógica dos celulares da maioria dos celulares disponíveis atualmente no Brasil.

Esboçando de forma concisa, a tecnologia $4 \mathrm{G}$ nos celulares, por exemplo, permite acesso rápido à internet e ao e-mail através da rede de telefonia celular no mundo todo. $\mathrm{E}$ a tecnologia $4 \mathrm{G}$ facilita a execução de várias tarefas ao mesmo tempo, pois uma conexão via 4G permite ao usuário navegar na internet e ainda falar ao telefone.

Os celulares convencionais permitem executar várias tarefas com mobilidade. Todavia, a tecnologia $4 \mathrm{G}$ permite realizar várias tarefas em ainda mais lugares, com conexão de alta velocidade, uma vez que as redes $4 \mathrm{G}$ permitem, por exemplo, efetuar downloads de voz e dados simultaneamente. Outro recurso disponível e atualmente viável pela velocidade da rede e recursos $4 \mathrm{G}$ é o de videoconferência. É possível participar de conferência e, durante o encontro virtual, compartilhar arquivos e assistir a um canal de televisão que passe por rede 
IP (de internet). A tecnologia permite ainda que mensagens de texto de celular (SMS) sejam convertidas em voz e direcionadas para caixas postais de telefones fixos e vice-versa. $\mathrm{O}$ sistema também pode ser compatível com fax, embora esta última seja uma tecnologia quase obsoleta. É importante destacara aqui, contudo, que algumas funções cuja rede 4G suporta só são exequíveis nos atuais smartphones.

Atualmente, pode-se navegar pela Internet com rapidez e facilidade com a maioria dos novos telefones - smartphones. A partir destes celulares, podemos saber onde estão outras pessoas, graças à construção de satélite em tecnologia GPS. Eles podem então dizer-se outros telefones estão na mesma área. Outra tecnologia de curto alcance que também é padrão na maioria dos celulares é o Bluetooth, cujas ondas de rádio permitem detectar a presença de outros telefones com Bluetooth e permite troca de arquivos num raio de 20 metros (HARVEY, 2009, Online).

Essas inovações tecnológicas têm permitido a concretização da ideia de instantaneidade - tecnologia push, que "empurra" a informação para o usuário. Essa tecnologia, em oposição à tecnologia pull, onde o usuário precisa ir atrás da informação, mudou a lógica da relação entre indivíduo e informação, tendo sido potencializada com o advento do smartphone (BORGES e JOIA, 2013).

Frente a todas estas possibilidades, entende-se que seu uso tende cada vez mais a maximizar processos nas empresas, tanto na comunicação externa com seus clientes e consumidores, bem como nas práticas internas de comunicação. Isso porque tais dispositivos possibilitam às empresas maior agilidade no trato e circulação da informação, clareza de detalhes dentre outros. Assim, obtêm maior vantagem competitiva a medida que permitem troca de informações e dados de forma móvel, segura, sem intermediários e instantânea.

Neste sentido, a análise dos impactos do uso deste dispositivo do âmbito das organizações, tanto nos processos de trabalho quanto no pós-trabalho torna-se importante, principalmente quando se propõe a uma análise micro de um fenômeno macro. Sendo assim, a seção seguinte ocupa-se de tal discussão.

\subsection{Celulares e organizações: tendências e impactos}

As tecnologias móveis têm cada vez mais sido utilizada nas empresas de forma estratégica, a fim de viabilizar processos e práticas cotidianas nas organizações, que antes eram realizadas de modo muito mais centralizado e desarticulado como, por exemplo, as próprias práticas comunicativas internas.

Lai e Katz (2012) discutem que, em se tratando de telefones celulares, há tendências e modalidades predominantes no uso desta modalidade de comunicação móvel, mesmo que as práticas de comunicação móvel em si continuem a mudar. As opções que são feitas por usuários para alcançar o ato de comunicação são de diversas modalidades possíveis. Além disso, os usuários são capazes de escolher uma entre uma infinidade de possibilidades que podem ser projetadas para as ferramentas e recursos disponíveis nestes dispositivos. Por sua vez, afetam suas ações de comunicação e reações.

Em relação ao uso com intensões organizacionais, de acordo com Kadyte (2010), as empresas podem utilizar tais tecnologias observando-se impactos de naturezas diversas. Primeiramente para o 'cliente', a medida que permitem aumentar o nível de serviço ao cliente, levando em conta o desejo do cliente de ser informado sobre cada novo produto, sobre reclamações feitas entre outros. Para os 'processos', quando simplificam e melhoram a qualidade dos processos internos e, consequentemente, torna-os mais visíveis e integrados para os clientes e colaboradores. Para os 'colaboradores', a medida que aumentam o número de ambientes de trabalho para aqueles funcionários que estão em mobilidade. Assim, as tecnologias móveis tendem a diminuir a porcentagem de interrupções de trabalho que ocorrem devido à complexidade do processo (quando se depende da tomada de decisão de outros que 
não estejam no ambiente), e a necessidade de coordenação e da variedade do meio de comunicação convencionais utilizados. E, por fim, para a 'melhoria das finanças da empresa', quando permite reduzir gradualmente os custos devido a redução do tempo dos processos (Incluindo o tempo de trabalho, interrupções, e tempo de viagem), despesas de viagem, etc. (KADYTE, 2010).

A utilização de dispositivos móveis nas empresas pode, portanto, trazer imensos benefícios, porém as principais vantagens estão associadas ao aumento da produtividade e eficiência nas transações, fazendo com que os funcionários e colaboradores possam trocar informações a qualquer tempo (anytime) e em qualquer lugar (anywhere) (BOTTENTUIT JUNIOR, 2008).

Isto alimenta, conforme discussão de Wilson et al. (2008), uma sensação maior de proximidade, que faz com que os interlocutores compreendam esta forma de comunicação como uma extensão física de seu eu. Conforme salientam, esta 'proximidade percebida' é uma construção assimétrica que define a percepção de uma pessoa de quão perto ou quão longe está de outra pessoa. Contudo, o que pode ser observado é que percepções de proximidade são naturalmente assimétricas; por exemplo, um analista de tesouraria pode perceber o gerente de contas como próximo sem este gerente ter percepções semelhantes em relação ao analista.

Os estudos de Ferrari (2005) e Kadyte (2004), Bottentuit Junior (2008, p. 8-9) elencam uma série de vantagens no uso de tecnologias móveis, o que se aplica sobremaneira aos telefones celulares, que as organizações podem conseguir:

- Os dispositivos móveis podem enviar fotos de alta definição, vídeos, apresentações no Power Point, notícias e mensagens;

- Fazer atualizações de moblogs (blogs atualizados a partir do dispositivo móvel);

- Editar galerias pessoais com arquivos de som e imagem, enviar músicas, customizar layouts de sites;

- Realizar pagamentos, consultar saldos e extratos para além de realizar transferências de valores entre contas;

- Permite que o funcionário inclua, apague e imprima (a partir da ligação do dispositivo móvel a uma impressora), lista de telefones e contatos;

- Trocar mensagens instantâneas através de aplicativos como: MSN, ICQ e Yahoo;

- Realizar reservas e compras de bilhetes, passagens e lugares de forma remota;

- Acionar serviços de agendas eletrônicas com serviços de alarmes sonoros, evitando desta forma esquecimentos de compromissos importantes;

- Realizar pedidos e atualizar preços de bases de dados na empresa;

- Localização de endereços e posicionamento através de do serviço de Global Positioning System (GPS) embutido em alguns dispositivos móveis;

- Acessar e enviar e-mails de forma rápida e prática;

- Tornar as informações disponíveis anywhere e anytime;

- Os funcionários podem receber treinamento ou formação a partir dos seus dispositivos móveis (m-learning). Esta formação poderá ocorrer tanto dentro da empresa como em casa em horário pós-laboral.

- Os funcionários, não somente consome a informação em movimento, mas também emitem um retorno que pode estar relacionado com a sua posição geográfica.

Apesar de tantas possibilidades, o que se questiona é até que ponto as empresas e, principalmente os gestores, estão preparadas para absorver e utilizar de forma eficaz tais tecnologias, além dos impactos deste uso no ambiente organizacional bem como os efeitos que extrapolam estes limites. 
Ferrari (2005) questiona inclusive se as empresas brasileiras têm condições de utilizar de forma plena todas as ferramentas existentes nos dispositivos móveis. Complementando tal indagação, Deibert e Rothlauf (2006) argumentam que indicadores quantitativos simples utilizados para mensurar processos podem ser observados para medir a eficiência da inserção dos dispositivos móveis como os telefones celulares nas organizações, entre eles os impactos no tempo, custo, taxas de erro, número de etapas reduzidas para o processo entre outros.

Como na atualidade, tecnologias como internet e celular se encontram cada vez mais inseridas no ambiente de trabalho, modificando o trabalho em si e sua dinamicidade, nem sempre se para de trabalhar após deixar o seu local de trabalho. O artefato tecnológico, neste estudo, o celular, pode ser acionado a qualquer momento, exercendo influência também na vida pessoal do trabalhador.

Nos estudos de Borges e Joia (2013, p. 598) há destaque para concepções como 'escravidão' e 'vício' causados pelo uso contínuo dos smartphones pelos gestores, mesmo no pós-trabalho. Os autores enfatizam que

\footnotetext{
Não obstante a sentença referente à escravidão ter surgido nos questionários apenas de forma moderada (média 3,7), nos discursos dos respondentes [...]. Apesar dos executivos não declararem de forma explícita que se sentem escravizados pelo uso da tecnologia, todos, sem exceção, afirmaram que precisam deixar o aparelho ligado para serem encontrados, tanto por colegas de trabalho, como no âmbito particular.
}

Portanto, este estudo pretende entender o comportamento dos gestores nos seus locais de trabalho, ou seja, no trabalho, e após a saída do seu local de trabalho, o pós-trabalho. Esta é é uma das mudanças significativas no mercado de trabalho em razão de diversas situações como concorrência, expectativa de melhoria de vida e uso de tecnologias como o celular.

Frente a essa realidade, este estudo vislumbra compreender alguns destes impactos sob a ótica dos gestores de João Pessoa, buscando assim investigar como as tecnologias móveis, em particular neste estudo os celulares, vêm afetando as práticas organizacionais em seus diversos âmbitos, enfocando neste momento nas práticas comunicativas internas da organização, no trabalho e no pós-trabalho.

\subsection{Qualidade vida no trabalho: evolução e conceitos}

A Qualidade de Vida no Trabalho pode ser definida como o conjunto das ações dentro da empresa que envolvem a implantação e manutenção de melhorias e inovações gerenciais, tecnológicas e estruturais no ambiente de trabalho (LIMONGI-FRANÇA, 1996; BARCAUI; FRANÇA, 2014). Para Davis (1966), a Qualidade de Vida no Trabalho - QVT refere-se à preocupação com o bem estar geral e a saúde do trabalhador.

Shiraishi et al. (1999) e Oliveira et al. (2013) ressaltam a importância da relação entre o indivíduo e a cultura existente na organização, definindo Qualidade de Vida no Trabalho como a gestão e educação para o bem-estar no trabalho, com decisões e escolhas baseadas na cultura organizacional e no estilo de vida dos diferentes segmentos ocupacionais.

Bonet-Porqueras et al. (2009) e Cavedon (2014) enfatizam ainda que a qualidade vida é uma percepção do indivíduo sobre sua posição de vida no contexto cultural, no sistema de valores que ele vive e com respeito a suas metas, e bem como nas expectativas, normas e preocupações profissionais e sociais. Um conceito extenso e complexo que engloba a saúde física, o estado psicológico, o nível de independência, as relações sociais, as crenças pessoais e a relação com características sobressalentes.

A qualidade de vida sempre foi objeto de preocupação do ser humano. Segundo Limongi-França (1997), a origem do conceito vem da medicina psicossomática, que propõe uma visão integrada e holística do ser humano em oposição à abordagem cartesiana que divide o ser humano em partes. Apesar de ser uma linha de estudo recente e necessitar de 
detalhamento de situações concretas para melhor compreensão do tema, a qualidade de vida no ambiente de trabalho tem sido vislumbrada informalmente desde o século XVIII, no período da Revolução industrial. Neste período, James Mill, Charles Babbage e Frederich Taylor, apesar de terem outros objetivos com suas teorias, trouxeram à tona fatores preponderantes e pioneiros para o bom desenvolvimento da atividade administrativa: condições adequadas de trabalho, incentivos e recompensas salariais adequadas, cuidados com a saúde do trabalhador.

Nadler e Lawer (1983) apud Fernandes (1996), Limongi-Franca (1997) e Rodrigues (1997), ilustram as diferentes fases - que se dão na metade do século XX - da concepção evolutiva da Qualidade de Vida no Trabalho oferecendo uma visão abrangente e esclarecedora:

- $\quad$ Qualidade de Vida no Trabalho como uma variável (1959 - 1972) - Reação do individuo no trabalho. Investigava-se como melhorar a qualidade de vida no trabalho para o individuo.

- $\quad$ Qualidade de Vida no Trabalho como uma abordagem (1969 - 1974) - Focado no individuo antes do resultado organizacional, porém, ao mesmo tempo, buscava-se trazer melhorias tanto ao empregado como à direção.

- $\quad$ Qualidade de Vida no Trabalho como um método (1972 - 1975) - Conjunto de abordagens, métodos e técnicas para melhorar o ambiente de trabalho e tornar o trabalho mais produtivo e satisfatório.

- $\quad$ Qualidade de Vida no Trabalho como um movimento (1975 - 1980) - Declaração ideológica sobre a natureza do trabalho e as relações dos trabalhadores com a organização. Os termos "administração participativa" e "democracia industrial" eram ditos como ideais do movimento QVT.

- $\quad$ Qualidade de Vida no Trabalho como tudo (1979 - 1982) - Como panaceia contra a competição estrangeira, problemas de qualidade, baixas taxas de produtividade, problemas de queixas e outros impasses organizacionais.

Neste milênio, há um esforço manifesto das organizações em sobreviver no mercado altamente competitivo, tendo como consequência o desgaste e o sacrifício desferido ao trabalhador contemporâneo. Mascarenhas e Vasconcelos (2004) e Barcaui e França (2014) afirmam que a efetividade econômica traduz-se em redução de custos e maximização dos lucros e, portanto, implicará na carga de trabalho dos colaboradores das empresas. Isto imputará sobre a efetividade comportamental, que não deve ser desconsiderada para o bemestar dos colaboradores e da organização. Por conseguinte, o tema Qualidade de Vida no Trabalho tem tomado espaço crescente e ator principal nas análises organizacionais que tenham o propósito de reavaliar a eficiência e a insatisfação no ambiente de trabalho.

Com relação a este debate, destaca-se que, em relação à qualidade de vida no trabalho, pode-se não somente analisa-la sob a ótica do uso de recursos tecnológicos comunicacionais móveis nas organizações como estender, maximizado pelas novas tecnologias comunicacionais móveis, o uso e as implicações no pós-trabalho. Uma vez que o gestor possui um celular e utiliza-se dele fora do ambiente de trabalho para gestão organizacional, seja no horário do expediente ou após, pode-se compreender que tais práticas estão atreladas à qualidade de vida do trabalhador. Isso porque uma vez que há o alargamento do trabalho para o pós-trabalho via telefones celulares, entende-se que tal exercício pode afetar positiva ou negativamente suas relações de trabalho, bem como suas relações sociais e familiares.

Nesta direção, Borges e Joia (2013) levantaram em suas pesquisas que como características positivas associadas ao uso do smartphone por gestores/executivos, há aspectos como a possibilidade de aumento de liberdade, independência, planejamento, continuidade e autonomia.

Esses profissionais reconhecem que a tecnologia smartphone contribui de forma 
importante para a flexibilização de seu tempo, tornando-os mais livres e com mais autonomia. Estas percepções de liberdade, independência e autonomia relacionam-se diretamente com a ideia de uma maior mobilidade, a qual está associada, consequentemente, a uma maior sobreposição dos tempos e espaços profissional e pessoal (BORGES e JOIA, 2013).

Já como pontos negativos, observaram que "esses profissionais reconhecem que tal ferramenta causa certa dependência, vício e escravidão à medida que se sentem obrigados, ainda que inconscientemente, a mantê-los sempre ligados e constantemente atualizados" (BORGES e JOIA, 2013). Este último pode estar diretamente relacionado aos possíveis impactos negativos de sua qualidade de vida no pós-trabalho uma vez que exigirá do gestor uma 'presença-ausente' em seus grupos sociais e familiares nos momentos em que está fora da organização.

Assim sendo, esta pesquisa pretendeu investigar, sob a ótica dos gestores, esses possíveis impactos oriundos de seus hábitos de uso dos telefones celulares em se tratando de assuntos de trabalho, seja no ambiente organizacional ou fora dele. Acredita-se que apesar de ser uma excelente ferramenta para auxiliar na gestão, tomada de decisões e resolução de problemas, elas podem estar afetando as relações sociais no pós-trabalho do gestor.

\section{PROCEDIMENTOS METODOLÓGICOS}

A pesquisa se caracterizou quanto a seu nível de aprofundamento por uma pesquisa 'exploratória' que, conforme salienta Gil (2008), tem por finalidade desenvolver, esclarecer ou modificar conceitos e ideias. Quanto ao seu procedimento técnico, a pesquisa classificouse como de pesquisa de campo. As pesquisas deste tipo caracterizam-se pela interrogação direta entre as pessoas cujo comportamento se deseja conhecer (TRIVIÑOS, 2006; MANGABEIRA et al. 2004; VERGARA, 2000). Quanto à abordagem e análise, a pesquisa se classificou ainda como sendo qualitativa, já que algumas questões que exijam maior subjetividade nas respostas.

Quanto a seleção dos sujeitos, neste estudo, optou-se pelos gestores de empresas e/ou organizações da cidade de João Pessoa/PB. Isso se deu pelo fato de que, rotineiramente, observa-se que os mesmos têm o hábito de utilizar seus telefones celulares para resolver questões empresariais não somente em seu horário de trabalho como também após o findar do mesmo. Tal realidade é tamanha que, atualmente, já existe legislação que possibilita o pagamento de horas-extras no caso em que trabalhadores necessitem rotineiramente usar seus telefones celulares e, consequentemente despender seu tempo pós trabalho, para resolução de problemas inerentes à sua empresa e/ou organização (PORTAL BRASIL, 2012; TST, 2016). Esta seleção ocorreu por acessibilidade e/ou conveniência, onde o pesquisador seleciona membros da população mais acessíveis, e que se adéquem ao perfil necessário à pesquisa (MATTAR, 1996; WHITE, 2009). Observou-se, como critério de escolha se, de fato, o possível entrevistado possui e faz uso de telefones celulares, preferencialmente smartphones, para que pudesse se enquadrar no perfil de uso de recursos acima citados. Como a escolha dos sujeitos se deu por acessibilidade, as escalações não se deram levando em conta classificação de área de atuação ou cluster específico. Entretanto, apenas gestores de micro, pequenas e médias empresas compõem a população do estudo, já que foram estes que permitiram o acesso dos pesquisadores.

A coleta de dados foi realizada por entrevistas com roteiro semiestruturado baseado na fundamentação teórica. Durante o processo de construção da mesma foi realizado um préteste no qual foram realizadas três entrevistas em um grupo específico de respondentes na cidade de João Pessoa-PB. Estes testes possibilitaram corrigir problemas de entendimento e realizar ajustes de linguagem, ordenação e interpretação do estudo.

A fim de se alcançar os objetivos da pesquisa realizou-se dez entrevistas em 
profundidade com gestores da cidade de João Pessoa/PB, os quais são responsáveis por funções referentes ao planejamento do nível estratégico e/ou tático das organizações em que trabalham de pequenos, médios e grandes portes na cidade pesquisada. Os dados foram coletados nos meses de junho e julho de 2013. As entrevistas, que seguiram o roteiro estabelecido foram gravadas e transcritas ipsis litteris, inclusive preservando possíveis equívocos de concordância ou construção das frases.

Os dados coletados foram trabalhados através da análise de discurso, baseando-se em estudos de autores como Dijk (2004), Mazière (2007) e Rey (2005). Segundo Van Dijk (2004), um aspecto inicial da análise do discurso é investigar como sequências de sentenças de um discurso são relacionadas a sequências de proposições subjacentes e como o significado de tais sequências é uma função do significado das sentenças constituintes ou proposições. $\mathrm{O}$ autor também ressalta que sentenças e proposições num discurso não estão ligadas somente por conectivos lógicos.

\section{RESULTADOS E DISCUSSÕES}

Os telefones celulares são artefatos presentes na vida das pessoas em quase $100 \%$ das localidades brasileiras, de acordo com a Anatel, em junho de 2016, o Brasil já contava com cerca de 253,4 milhões de aparelhos celulares ativos (TELECO, 2016). Neste contexto, a análise de como tal dispositivo pode estar influenciando e impactando no ambiente organizacional torna-se atrativa à medida que sendo a organização uma unidade sistêmica onde todos os processos acabam por se interinfluenciarem, possíveis impactos oriundos do uso deste dispositivo na comunicação interna para quaisquer finalidades, resultará em aspectos positivos e talvez até mesmo negativos para as empresas e seus colaboradores.

É neste sentido que a presente pesquisa buscou avaliar, por meio de entrevistas de aprofundamento, como os gestores da cidade de João Pessoa/PB percebem os impactos da posse e uso dos telefones celulares para comunicação interna organizacional e discutir como os telefones celulares podem afetar o cotidiano dos mesmos no pós-trabalho, quando o artefato é utilizado para assuntos profissionais fora do horário e ambiente de trabalho.

Logo, a discussão dos resultados pode ser dividida em dois momentos, o primeiro quando se analisa o uso do telefone celular como artefato de tomada de decisão e suporte a operacionalização das atividades organizacionais, e o segundo momento quando se discute como os telefones celulares podem afetar o cotidiano do gestor no pós-trabalho.

Ressalta-se que, a fim de se preservar o anonimato e os direitos dos participantes da pesquisa, tais indivíduos foram identificados como como Gestor 1, 2, 3, etc. Contudo, destaca-se que a integridade dos diálogos no que se refere à linguagem utilizada foi preservada.

A fim de se compreender melhor as falas dos participantes, cabe caracterizar tais sujeitos quanto ao seu nível de escolaridade: sete dos dez entrevistados têm curso superior completo e dois em curso.

Pode-se perceber que cinco dos entrevistados atuam no nível estratégico e os demais no nível tático, desse modo todos são responsáveis por processos de tomadas de decisão em seus cargos. Associado a este dado, como são responsáveis pelo processo de tomada de decisão em seus cargos, então esses sujeitos supostamente fazem uso ou têm a necessidade de fazerem uso das mais atuais tecnologias disponíveis no telefone celular.

\subsection{Telefones celulares e o suporte a operacionalização das atividades organizacionais}

Nos primeiros momentos da entrevista buscou-se discutir com os participantes sobre a contribuição do telefone celular para o andamento das atividades, e como os mesmos dão suporte à operacionalização de resoluções cotidianas de tarefas, funções e processos organizacionais. Seguem alguns trechos que ilustram a fala dos gestores acerca do 
questionamento:

Facilita. Todas minhas decisões podem ser tomadas em mobilidades, como as que não precisam da presença direta da pessoa, algumas vendas de apartamento, alguns fechamentos de compra de material, contato em todos os sentidos (Gestor 3)

Bastante [...] Em relação à franquia, são decisões que precisam ser tomadas. Em relação ao funcionário, que tem que mudar a rotina do trabalho, ai tem que pegar o celular para falar com funcionários que estão fora da empresa. Com fornecedores também, alguma coisa que quebra na loja o contato é por celular (Gestor 6)

Sim. Pois no meu ramo que é produção de eventos surgem diversos itens, detalhes, diferentes fornecedores que irá depender também da escolha do cliente, então muitas vezes não é necessário ir pessoalmente ao fornecedor para contratar algum material gerando uma otimização do tempo. Outra facilidade é para quem é cliente que muitas vezes não tem tempo em horário comercial e pelo celular posso estar em qualquer lugar que poderei tirar uma dúvida que ela esteja precisando ou dar uma indicação de como resolver o problema que ele tenha (Gestor 8)

Dos trechos acima, pode-se perceber, juntamente com as demais entrevistas, que de forma unânime considera-se que o telefone celular facilita as atividades organizacionais. No sentido de como este artefato age no suporte à operacionalização, fica evidenciado sua ajuda em aspectos como: nas resoluções de conflitos (algum equipamento que não funciona na empresa, mudanças em horários de trabalhos dos colaboradores, contato com franquia e fornecedores); nas práticas internas da empresa (delegação de funções, comunicação de orientações e lembretes, andamento de processos e atividades inacabadas, pesquisa de satisfação do cliente pelo celular) e nas negociações (vendas de apartamentos, fechamentos de compras, pagamento de boletos, negociação de preço com fornecedores, negociação com clientes).

Os dados coletados nas entrevistas corroboram com o pensamento de Kadyte (2010) quando este afirma que as empresas podem utilizar tal tecnologia observando-se impactos nas naturezas referentes aos clientes, para os processos organizacionais e para os colaboradores. Conforme Bottentuit (2008), as principais vantagens da utilização do artefato tecnológico concentram-se no aumento da produtividade e eficiência nas transações, por possibilitar aos gestores trocarem informações a qualquer tempo (anytime) e em qualquer lugar (anywhere).

Neste ensejo de impactos positivos ocasionados pelo uso do telefone celular na organização, Mooallem (2008) e Fay (2005) chamam nossa atenção para que, embora este artefato auxilie muito no dia a dia das empresas, seu uso também pode impactá-la negativamente em alguns aspectos. Desse modo, a fim de se discutir quais tipos de impactos negativos o celular pode ocasionar na organização, foi questionado durante a entrevista aos gestores participantes se os mesmos achavam que o uso do telefone celular dentro da empresa poderia gerar algum impacto negativo. Observe-se em seguida algumas falas acerca do tema supracitado:

Sim. Existe uma grande dificuldade em restringir o uso do telefone celular para assuntos estritamente relacionados ao ambiente de trabalho. Neste sentido, sua utilização pode ocasionar perda de tempo de trabalho, bem como, no processo produtivo, desvios de atenção e aumento do risco de acidentes (Gestor 1) 
Tudo mal usado, ou usado indevidamente compromete [...] celular do mesmo jeito, a única coisa que monitoro é a conta do celular e acompanho a variação da conta, o correto seria cada gerente estar com o celular, mas os gerentes dizem que eles são muito requisitados então fica difícil eles ficarem com o celular, ficaria improdutivo eles estarem acompanhando o celular, então o celular mal utilizado compromete a empresa na conta do celular (Gestor 2).

Sim. Quando o assunto não diz respeito à empresa. Por exemplo, uma amiga ou familiar liga para conversar sobre coisas pessoais (Gestor 8).

Salienta-se que dois gestores não concordaram com a ideia de que o telefone celular pode impactar negativamente na organização por relatarem que há maneiras de se administrar o uso. Já para 8 participantes, o uso do telefone celular impacta negativamente no aspecto produtivo organizacional quando se refere apenas ao mau uso do aparelho, como a utilização do telefone celular para assuntos não profissionais ou não relacionados ao ambiente de trabalho. Como consequência deste mau uso, os gestores destacaram a perda do tempo de trabalho, perda no processo produtivo, aumento nos desvios de atenção, aumento dos riscos de acidentes e elevação dos custos organizacionais (aumento na conta do celular).

Ao se questionar acerca de efeitos positivos e negativos do uso do telefone celular e implicações do uso celular nos processos decisórios da empresa junto a seus clientes externos (seus stakeholders), os gestores associam o uso do celular e o seu impacto positivo aos clientes externos, fornecedores e usuários finais da cadeia produtiva, conforme mostram os trechos a seguir:

[...] Nosso espaço físico é muito amplo e, a muitos de nós trabalham locomovendo-se pela empresa, assim, dificultando o acesso ao cliente. $O$ telefone celular, facilita os acessos e, com certeza influencia a satisfação do cliente (Gestor 1).

[...] Facilita nossa comunicação com os fornecedores e com a matriz, logo, os clientes são melhores atendidos, quando existe um problema o celular melhora a eficácia do solucionamento (Gestor 5).

A vantagem é em relação aos fornecedores, as pessoas que o contato tem que ser rápido e direto. A maioria dos contatos com os fornecedores, eles têm apenas celular (Gestor 6).

[...] O cliente que muitas vezes não tem tempo em horário comercial e pelo celular posso estar em qualquer lugar que poderei tirar uma dúvida que ele esteja precisando [...] (Gestor 8).

Verifica-se que todos os participantes concordam que, dentre os efeitos positivos proporcionados pelo uso do celular, encontram-se a maior facilidade em comunicar-se com o cliente/usuário final, influência na satisfação do cliente, melhoria no atendimento aos clientes, maior facilidade em comunicar-se com fornecedores e matriz, e, por fim, uma otimização do tempo do cliente e da empresa. Isso se dá pelo fato deles não precisarem se deslocar para solucionar alguns problemas, ou seja, há uma maior 'sensação de proximidade', aspecto este muito explorado nos estudos de Wilson et al. (2008).

Ainda sobre aspecto, Kadyte (2010), afirma que o telefone celular pela empresa, impacta positivamente o cliente ao aumentar o nível de serviço ao cliente, levando em conta o 
desejo do cliente de ser informado sobre cada novo produto, sobre reclamações feitas entre outros. Levando-se em consideração o autor supracitado, pesquisas subsequentes podem procuram estudar formas de melhorar a comunicação da empresa com seus clientes de maneira que ambos obtenham otimização nas suas questões.

Buscando averiguar melhor como e em que medida os telefones celulares dão suporte à operacionalização de resoluções cotidianas de tarefas, funções e processos organizacionais, indagaram-se aos gestores quais seriam as vantagens da empresa utilizar o telefone celular mesmo já existindo o telefone fixo dentro da organização. Salienta-se que com esta pergunta, podemos perceber e analisar a conjuntura atual das organizações, da cidade de João Pessoa, no que diz respeito ao conhecimento e uso das séries de vantagens disponibilizadas pelas tecnologias móveis (como o telefone celular) elencadas no estudo de Bottentuit Junior (2008), citado anteriormente na revisão da literatura do presente artigo. Observa-se abaixo as algumas falas dos gestores quanto ao assunto abordado.

Devido à mobilidade, que nos permite fazer duas coisas ao mesmo tempo (Gestor 2).

Eu acho que é mais por conta da facilidade, até para cotação de preço a maioria dos vendedores usam celular, ai a conta fica mais barata. Hoje em dia todo mundo usa mais celular, então fica mais econômico utilizar o celular(Gestor5).

Mobilidade. Telefone celular fica ligado 24hrs por dia todos os dias da semana, o fixo apenas em horário comercial. Hoje no aparelho celular você tem a utilização da internet como divulgação da empresa, visualização dos e-mails em tempo real, entre outros (Gestor 8).

As principais vantagens listadas pelos gestores de João Pessoa do uso do celular referem-se, principalmente, à mobilidade (comunicação móvel), facilitação da comunicação com os clientes e fornecedores, melhoria na viabilização dos processos e práticas cotidianas da empresa e 'melhoria das finanças da empresa' - quando permite reduzir gradualmente os custos com comunicação. Contudo, nota-se que a maioria dos gestores ainda não conhecem todas as possibilidades disponíveis nas tecnologias móveis ou utilizam uma grande parte dos recursos vantajosos listadas no estudo de Bottentuit Junior (2008) como, por exemplo, realizar pagamentos, consultar saldos e extratos para além de realizar transferências de valores entre contas e acionar serviços de agendas eletrônicas com serviços de alarmes sonoros, evitando desta forma esquecimentos de compromissos importantes.

Ainda buscando conhecer melhor como acontece a utilização por parte dos gestores dos recursos disponíveis no artefato tecnológico do telefone celular que promovem maior vantagem competitiva, indagou-se os entrevistados sobre quais destes recursos de comunicação (tais como internet, Bluetooth, mensagens de textos e vídeo, apresentação Power Point, Realização de pagamentos, etc.) já são utilizados pelos mesmos, que responderam:

Atualmente utilizamos internet, intranet, e-mails, telefonia fixa, telefonia móvel, teleconferências, webex, mensagens de texto instantânea, mensagem de vídeo (Gestor 1).

Apenas ligação convencional (Gestor 3).

Internet, Bluetooth, mensagens de textos-sms, ligação convencional, realização de pagamentos e divulgação de fotos dos eventos (Gestor 8). 
A partir dos discursos obtidos dos gestores, pode-se constatar que apesar de alguns destes já utilizarem recursos além da ligação convencional, como as mensagens de texto e vídeo, Bluetooth, internet (e-mail, pagamentos, divulgação da empresa) e teleconferências, a grande parte destes profissionais ainda utiliza basicamente a ligação convencional. Refletindo-se acerca da questão, pode-se chegar a dois motivos para tal conjuntura: o primeiro seria, segundo a visão dos participantes, devido ao porte da organização. Para eles, as micros e médias empresas não necessitam das evoluções tecnológicas do celular por seus processos operacionais serem simples. Essa percepção se dá como consequência do segundo motivo, que é justamente o desconhecimento dos próprios recursos tecnológicos que o telefone celular disponibiliza e como estes podem beneficiar a organização em sua vantagem competitiva, já que proporciona maior rapidez e eficácia na resolução de suas atividades cotidianas.

Para finalizar o primeiro momento da análise, observando-se ainda o uso dos telefones celulares como artefato de suporte à tomada de decisões em mobilidade durante o horário de trabalho, analisou-se o costume dos gestores de se comunicar com seus subordinados por meio do telefone celular quando ambos estão dentro do espaço da organização, e quando apenas os subordinados estão dentro do ambiente de trabalho. As falas a seguir tratam do costume de se comunicar com os subordinados quando ambos estão dentro da organização:

Não costumo. Para me comunicar com eles, nós temos um ramal no telefone fixo (Gestor 6).

Algumas vezes. Mas utilizamos mais rádio para nos comunicar com o funcionário do estoque (Gestor 8).

Não, só quando estou em reunião ai para não sair eu ligo. Isso é mais para grandes empresas (Gestor 2).

Quando foi questionado aos gestores se os mesmos quando se encontram fora da empresa, mas em horário de trabalho, costumam utilizar o telefone celular para falar com seus subordinados, obteve-se os seguintes relatos:

Costumo, quando tem alguma coisa para resolver pendente, alguma coisa que estava sendo para ser realizado aqui no restaurante. Ou alguma coisa que eu me lembre, depois que eu saio daqui (Gestor 5).

Não é constante, quando utilizo é quando esqueci de dar andamento de alguma função (Gestor 6).

Sim. Eu estava no banco e minha funcionária em uma loja de aviamentos onde não tinha o item que eu havia pedido, no momento ela ligou falou outras opções que havia e eu no mesmo momento decidi por outro item, ou como já aconteceu ter que pedir para o meu funcionário mudar as prioridades de serviço passadas para ele no início do dia por motivo maior (Gestor 8).

Posterior à leitura dos discursos, notou-se que os gestores entrevistados não costumam utilizar o telefone celular para se comunicar com seus subordinados quando ambos estão dentro da organização. Tal conjuntura pode ser consequência do porte da organização no qual os mesmos trabalham, já que defendem que em uma pequena e média empresa não há tanta necessidade de se comunicar pelo celular, tendo em vista que os colaboradores encontram-se próximos a eles. Uma segunda conjectura defendida pelos gestores participantes centra-se no 
fato que dentro da organização existem ramais (nos telefones fixos) ou rádios, diminuindo assim o custo financeiro das ligações dos celulares.

Já quando se aborda o costume dos gestores de utilizarem o telefone celular para falar com seus colaboradores quando estão fora da empresa, levantou-se que sete dos participantes mantêm este costume. Na maioria das vezes, pode-se perceber que isso ocorre devido à necessidade de resolver problemas pendentes, de finalizar algumas transações de negócios e de dar andamentos de atividades. Adiante, a abordagem das possíveis implicações do uso dos telefones celulares como continuidade da gestão no pós-trabalho é apresentada.

\subsection{Telefones celulares e o cotidiano do gestor no pós-trabalho.}

O segundo momento da pesquisa diz respeito a como os telefones celulares podem afetar o cotidiano do gestor no pós-trabalho já que, atualmente, devido à mobilidade do artefato, nem sempre o gestor para de trabalhar após deixar o seu local de trabalho. Isto porque é possível acionar o celular a qualquer momento, o que ocasiona prejuízo na qualidade de vida do trabalhador. Neste ensejo, indagou-se aos gestores acerca dos seus costumes de utilizar o telefone celular para assuntos de trabalho, quando os mesmos se encontram fora da empresa e fora do horário de trabalho. Observou-se que sete dos gestores afirmaram ter o costume de utilizar o telefone celular para assuntos de trabalho mesmo após o término de seu expediente. Observe-se os relatos que corroboram tal realidade:

Sim, constantemente. Isso já aconteceu no fechamento de vários negócios, fora do horário da empresa (Gestor 4).

Utilizo, mais para falar com a gerente [nome da gerente]. Questões de alguma coisa que quebrou na loja que tem que ser resolvido logo, uma autorização de pagamento de alguma coisa, para não atrasar o serviço (Gestor5).

Bastante. Ela já diminui bastante isso, porque antes era mais frequente. Eu estava fora da loja super cansada já tinha terminado meu expediente, e os funcionários ligavam pra mim qualquer coisa que a própria supervisora que estava dentro da loja poderia resolver (Gestor 6).

Posteriormente, buscou-se questionar se os mesmos acreditam que o uso do celular fora do horário de trabalho traz algum benefício a eles. Nesse sentido, segue os trechos de algumas entrevistas.

Traz. Um corretor de imóveis para em um domingo, e quer saber alguma informação do apartamento que está mostrando. Quando eu preciso que a engenheira da obra em vez de ir direto para a obra, venha direto para o escritório. São contatos que normalmente têm na empresa (Gestor 3).

Não, é cansativo, não é muito bom não, eu já tenho uma carga muito completa então quando você sai quer descansar um pouco (Gestor 6).

Por um lado sim, pois podemos conseguir através desse atendimento rápido, não perdemos reuniões, por outro lado acabamos não tendo horário de início e término de serviço no dia (Gestor 8).

A partir dos discursos supracitados, com o intuito de analisar melhor os impactos do uso do telefone celular no pós-trabalho, indagou-se aos gestores sobre a existência de queixas por parte dos familiares diante deste contexto, os quais relataram: 
Muito, muito, muito. Eu moro com minha mãe ainda, e ela fica dizendo: ah fala para eles que já acabou seu expediente, que tem outras pessoas capacitadas. Então complica um pouco, porque você tem outras coisas na sua vida, tem a sua família, então fica uma sobrecarga (Gestor 6).

Sim. Mas poucas vezes, tenho 2 números um pessoal e um para trabalho. Só que as vezes amigos e familiares viram clientes e ligam para o meu número pessoal em qualquer horário e dia de semana ou fim de semana (Gestor 8).

Por fim, como complementação do debate anterior, questionou-se os gestores se também já houve queixas no seu círculo social sobre o uso do telefone celular para assuntos de trabalho após o término do horário de trabalho. De forma similar aos relatos supracitados, observa-se os trechos a seguir:

É isso atrapalha, é onde está gerando um maior impacto, por o celular ser um instrumento extremamente mau educado. Acho que o celular é um equipamento que devemos aprender a como utilizar melhor (Gestor 3).

Quando você está fora da empresa, não é muito positivo não, então esse impacto é bastante considerável (Gestor 6).

Desse modo, corroborando a revisão de literatura, o uso dos telefones celulares tem se expandindo-se cada vez mais para além do ambiente e do horário de trabalho dos gestores e de todos os que trabalham ocasionando assim, progressivamente, um prejuízo na qualidade de vida dos mesmos, posto que seus horários de descanso encurtam-se cada vez mais. Significa que, embora o telefone celular possa trazer inúmeras vantagens competitivas para a empresa ao aumentar consideravelmente sua taxa produtiva e seu lucro, acarreta igualmente prejuízo à vida social e familiar dos seus colaboradores.

\section{CONCLUSÃO}

Posterior às discussões dos resultados, fica evidenciado o auxílio que o telefone celular promove nos processos organizacionais, como por exemplo, nas resoluções de conflitos, nas práticas internas da empresa (delegação de funções, comunicação de orientações e lembretes, andamento de processos e atividades inacabadas, pesquisa de satisfação do cliente pelo celular) e nas negociações (vendas de apartamentos, fechamentos de compras, pagamento de boletos, negociação de preço com fornecedores, negociação com clientes). Além destes benefícios trazidos pelo uso do telefone celular na organização, a pesquisa destaca ainda a maior facilidade em comunicar-se com o cliente/usuário final, influência na satisfação do cliente, melhora no atendimento aos clientes, maior facilidade em comunicar-se com fornecedores e matriz, e, por fim, uma otimização do tempo do cliente e da empresa, por eles não precisarem se deslocar para solucionar alguns problemas.

Neste ensejo dos ganhos que o uso do telefone celular gera para as empresas, observou-se com a pesquisa que um mau gerenciamento deste uso também impacta negativamente no aspecto produtivo organizacional, visto que o uso do celular para assuntos não profissionais acarreta em perda do tempo de trabalho, aumento nos desvios de atenção, aumento dos riscos de acidentes e elevação dos custos organizacionais (aumento na conta do celular).

Quando analisado ainda os possíveis impactos negativos originados do uso do telefone celular, é de suma importância destacar a alta e frequente incidência do uso deste pelos colaboradores em seu pós-trabalho devido à mobilidade do artefato nem sempre o gestor para 
de trabalhar após deixar o seu local de trabalho, visto que, o celular pode ser acionado a qualquer momento, o que ocasiona prejuízo direto em sua qualidade de vida e bem-estar. Salienta-se ainda que nenhum gestor recebe alguma remuneração extra pelo tempo de trabalho fora do seu horário de expediente, e que estes sofrem frequentemente reclamações por parte dos familiares e amigos quanto ao seu uso em tempos de lazer e convívio.

A presente pesquisa procurou averiguar ainda até que ponto as empresas estão preparadas para absorver e utilizar de forma plena todas as ferramentas existentes nos dispositivos móveis a fim de impactar no tempo, custo, taxas de erro e redução de número de etapas para os processos. Desse modo, pode-se constatar que apesar de alguns destas já utilizarem recursos além da ligação convencional, como as mensagens de texto e vídeo, Bluetooth, internet (e-mail, pagamentos, divulgação da empresa) e teleconferências, a grande parte dos gestores se limita a utilizar apenas a ligação convencional. A pesquisa demonstra que esta limitação ocorre possivelmente por um desconhecimento por parte dos gestores dos recursos tecnológicos que o telefone celular disponibiliza e como estes podem estar beneficiando a organização em sua vantagem competitiva, por proporcionar maior rapidez e eficácia na resolução de suas atividades cotidianas.

Em suma, pode-se observar que a pesquisa conseguiu responder ao seu objetivo geral de analisar os impactos da posse e uso dos telefones celulares para a comunicação interna organizacional, no trabalho e no pós-trabalho. E conclui-se a grande importância de continuar e desenvolver novas pesquisas referentes ao uso do artefato tecnológico em questão, o telefone celular, como suporte das operações organizacionais, principalmente em relação ao uso nas pequenas empresas. Isso se deve ao fato de ter ficado evidenciado nas entrevistas que atualmente, na cidade de João Pessoa, apenas as grandes empresas conhecem e utiliza o telefone celular para pagamentos, comunicação dentro da própria organização, teleconferências, vídeos, entre outros recursos.

Concomitante a esta análise, reflete-se também a necessidade de se observar mais cuidadosamente os impactos negativos que o uso do artefato em questão provoca, já que com o avanço dos recursos dos telefones celulares houve uma modificação na dinâmica do trabalho, de modo que os profissionais não deixam de trabalhar quando terminam sua carga horária. Esta é uma consequência direta da mobilidade do artefato que permite a comunicação móvel em tempo real - embora comunicação assíncrona também seja possível através de outros recursos do dispositivo.

A consequência mais evidente presente nas falas dos gestores diz respeito a diminuição da qualidade de vida dos mesmos, devido a redução do seu tempo livre de lazer, o prejuízo na sua vida social, entre outros âmbitos referentes a QVT (Qualidade de Vida do Trabalho). Sendo assim, fica a oportunidade de pesquisas que objetivem encontrar formas de se aproximar de um equilíbrio entre o uso do celular para vantagem competitiva sem prejudicar a qualidade de vida dos trabalhadores.

Assim, o estudo pode contribuir para pesquisas futuras, as quais poderia procurar avaliar e criar maneiras e estratégias de se minimizar o mau uso do telefone celular nas organizações, proporcionando às organizações novas formas de otimizar o processo produtivo refletindo diretamente no ganho da sua competitividade. Reflete-se também acerca da necessidade de se pesquisar mais sobre o impacto negativo proposto por Fäy (2005), que acredita que o uso do celular pode gerar ruídos que dificultam as comunicações entre setores ou colaboradores localizados em diferentes espaços geográficos, já que nas falas dos entrevistados não foi evidenciado nenhum discurso que corroborasse com seu pensamento.

Como limitações da pesquisa, aponta-se a dificuldade de agendamento com gestores que se predispusessem a doar um pouco de seu tempo para responder à pesquisa, bem como ausência de possíveis instrumentos prévios de pesquisas qualitativas já validados que objetivam analisar a relação do uso dos celulares e seus impactos nos trabalhadores não 
somente no ambiente de trabalho, mas também no pós-trabalho.

Por fim, para estudos futuros sugere-se a inclusão de debates como a gestão do conhecimento tendo como suporte tal dispositivo já que, embora não tenha sido foco deste estudo, possivelmente é uma das implicações do uso de novas tecnologias digitais móveis no cotidiano das organizações. A análise desta mesma problemática por parte dos demais colaboradores da organização pode trazer resultados interessantes. 


\section{REFERÊNCIAS BIBLIOGRÁFICAS}

BARCAUI, A.; FRANÇA, A. C. L. Estresse, enfrentamento e qualidade de vida: um estudo sobre gerentes brasileiros. Revista de Administração Contemporânea, v. 18, n. 5, p. 670694, 2014.

BONET-PORQUERAS, R. et al. Turno nocturno: un factor de riesgo en la salud y calidad de vida del personal de enfermería. Enfermería Clínica, v. 19,n. 2, p. 76-82, march, 2009.

BORGES, Ana Paula; JOIA, Luiz Antônio. Executivos e smartphones: uma relação ambígua e paradoxal. Revista Organizações \& Sociedade. v. 20, n. 67. Salvador, 2013.

BOTTENTUIT Junior, J. B. Dispositivos e tecnologias móveis nas empresas: novas possibilidades para os negócios na era da informação. Revista negócios e tecnologia da informação. v. 3, n. 1. Curitiba, 2008, p.1-14.

BRASIL, Portal. Uso de celular fora do trabalho é hora extra. 2012. Disponível em: http://www.brasil.gov.br/infraestrutura/2012/09/uso-de-celular-fora-do-trabalho-e-hora-extra. Acesso em 15/08/2016.

CAVEDON, N. R.A qualidade de vida no trabalho na área da Segurança Pública: uma perspectiva diacrônica das percepções olfativas e suas implicações na saúde dos servidores. n, v. 21, n. 68 , p. 875-892, 2014.

COELHO, P. Um mundo em constante evolução. 2006. Disponível em: http://www.pedrocoelho.com/jsite/index.php?option=com_content\&view=article\&id=47:tecn ologias-de-comunicacao-movel. Acesso em: 30/05/2009.

DAVIS, L. E. The design of jobs. Industrial Relations, p. 21-45, out. 1996.

DEIBERT, S.; ROTHLAUF, F. On the benefit of using mobile technologies in business processes, Mannheim: University of Mannheim, 2006 Disponível em: http://wi.bwl.unimainz.de/Dateien/Working_Paper_eChallenges06.pdf . Acesso em: 12/04/2011.

DIJK, T. A. V. Cognição, discurso e interação. 6. ed. São Paulo: Contexto, 2004.

FÄY, Eric. Diálogo e empresa virtual: Alice na "Virtual Global Company". In: SOUZA, Marcio Vieira. A comunicação na Aldeia Global: cidadãos do planeta face à explosão dos meios de comunicação. Petrópolis: Vozes, 2005.

FERNANDES, E. Qualidade de vida no trabalho: como medir para melhorar. Salvador:

Casa da Qualidade Editora Ltda., 1996.

FERRARI, P. Sua empresa está pronta para produzir conteúdos para dispositivos móveis?. 2005, Disponível em: www.aberje.com.br/novo/revista/3_2005/interatividade.pdf. Acesso em 12/04/2011.

GIL, A. C. Métodos e técnicas de pesquisa social. 6. ed. Sao Paulo: Atlas, 2008.

HARVEY, M. The future of social networking: mobile phones. TimesOnline. Disponível em: http://technology.timesonline.co.uk/tol/news/tech_and_web/article3897340.ece . Acesso em 09/05/2009.

IÑIGUEZ, L. Manual da análise do discurso em ciências sociais. São Paulo: Vozes, 2004.

KADYTE, V. Uncovering the potential benefits of mobile technology in business relationship context: a case study. In 13th European Conference on Information Systems 2004 Disponível em: http://is2.1se.ac.uk/asp/aspecis/20040078.pdf . Acesso em: 10/04/2010.

LAI, Chih-Hui; KATZ, James E. Are we evolved to live with mobiles? An evolutionary view of mobile communication. Periodica Polytechnica, v. 20, n. 1. 2012. p. 45-54.

LEMOS, A. Ciberespaço e tecnologias móveis: processos de territorialização e desterritorialização na cibercultura. In: COMPÓS - Encontro Anual, 2006, Bauru-SP. Anais eletrônicos. Bauru: Associação dos Programas de Pós-Graduação em Comunicação, 2006. LIMONGI-FRANÇA, A. C. Indicadores empresariais de qualidade de vida no trabalho: esforço empresarial e satisfação dos empregados no ambiente de manufaturas com certificação ISO 9000. 1996. 232 pp. Tese (Doutorado em Administração) - Universidade de 
São Paulo, São Paulo, 1996.

LIMONGI-FRANÇA, A. C. Qualidade de vida no trabalho: conceitos, abordagens, inovações e desafios nas empresas brasileiras. Revista Brasileira de Medicina Psicossomática, Rio de Janeiro, v. 1, n. 2. abril/maio/jun. 1997.

MACHADO, Renato. Sistemas de telefonia celular no Brasil. Disponível em: http://coral.ufsm.br/gpscom/professores/Renato\%20Machado/Telefonia/TelCelular17Renato. pdf. Acesso em 18/08/2016.

MANGABEIRA, W. C. et al. Computer and qualitative research: adoption, use, and representation. Social Science Computer Review, Thousand Oaks, v. 22, n. 2, p. 167-178, summer, 2004.

MARCONI, M. A.; LAKATOS, E. M. Metodologia científica. 4. ed. São Paulo: Atlas, 2004. MASCARENHAS, A. O.; VASCONCELOS, F. C. Tecnologia na gestão de pessoas:

estratégias de auto-atendimento para o novo RH. São Paulo: Pioneira Thomson Learning, 2004.

MATTAR, F. N. Pesquisa de marketing. Edição Compacta. São Paulo: Atlas, 1996.

MOOALLEM, Jon. The afterlife of cellphones. the New York Times. 2008. Disponível em: http://www.kiwanja.net/database/article/article_cellphone_afterlife.pdf. Acesso em 15/04/2010.

OLIVEIRA, J. S. et al. Qualidade de vida no trabalho: um estudo sobre a avaliação por agentes de segurança penitenciária. RAUnP - Revista Eletrônica do Mestrado Profissional em Administração da Universidade Potiguar, v. 5, n. 2, p. 63-77, 2013.

RODRIGUES, M. V. C. Qualidade de vida no trabalho: evolução e análise no nível gerencial. Petrópoles: Vozes, 1997.

SHIRAISHI, G.; HAMZA, M.; TSAI, J.; MURITIBA, S. Qualidade de vida no trabalho uma análise do ponto de vista dos seus gestores. I SEMEAD Jr., out. 1999.

TELECO. Estatísticas de Celulares no Brasil. Disponível em:

http://www.teleco.com.br/ncel.asp. Acesso em 18/08/2016.

TRIVIÑOS, A. N. S. Introdução à pesquisa em ciências sociais. São Paulo: Atlas, 2006.

TST, Tribunal Superior do Trabalho. Alterações, cancelamentos e novas Súmulas do Tribunal Superior do Trabalho. Disponível em: http://www.tst.jus.br/documents/10157/2b196ee15d44-43ea-b197-51ba0e30da21. Acesso em 18/08/2016.

VERGARA, S. C. Projetos e relatórios de pesquisa em administração. São Paulo: Atlas, 2000.

WHITE, G. K. An on-line survey of food and beverage consumers on the Internet: an evaluation of the survey methodology. Disponível em: http://marketing-

bulletin.massey.ac.nz/V14/MB_V14_A3_White.pdf. Acesso em: 03/02/ 2009.

WILSON, Jeanne M. et al. Perceived proximity in virtual work:: explaining the paradox of far-but-close. Organization Studies, 2008. 